Schuur Hospital, for permission to publish. We acknowledge with thanks the continued financial support of the Council for Scientific and Industrial Research and the City Council of Cape Town.

\section{REFERENCES}

Braunwald, E., Brockenbrough, E. C., and Frye, R. L. (1962). Circulation, 26, 166

— and Ebert, P. A. (1962). Amer. f. Cardiol., 10, 489.

- Lambrew, C. T., Rockoff, S. D., Ross, J., and Morrow, A. G. (1964a). Circulation, 30, Suppl. No. 4, p. 3.

(1964a). Circulation, 30, Suppl. No. 4, p. 3. J. W., Mason, D. T., Ond Fort, L., III (1964b). Ibid., 29, 422. Brotmacher, L. (1957a). Brit. heart F., 19, 559.

Brotmacher, L. (1957a). Brit.

Criley, J. M., Lewis, K. B., White, R. I., and Ross, R. S. (1965). Circulation, 32,881 .

Goodwin, J. F. (1964). Brit. med. f., 1, 1527.

Hancock, E. W., and Fowkes, W. C. (1966). Circulation, 33, 383.
Harrison, D. C., Braunwald, E., Glick, G., Mason, D.T., Chidsey, C. A., and Ross, J., jun. (1964). Ibid., 29, 84.

Lewis, R. P., Bristow, J. D., Farrehi, C., Kloster, F. E., and Griswold, H. E. (1965). Amer. F. Med., 38, 842.

Marcus, F. I., Westura, E. E., and Summa, J. (1964). Amer. Heart f.,

Mason, D. T., Braunwald, E., and Ross, J., jun. (1966). Circulation, 33, 374.

Nellen, M., Beck, W., Vogelpoel, L., Swanepoel, A., and Schrire, V. (1965). S. Afr. med. 尹., 39, 304.

O'Donnell, T. V., and Mcllroy, M. B. (1962). Amer. Heart F., 64, 347. Pierce, G. S., Morrow, A. G., and Braunwald, E. (1964). Circulation, 30, Suppl. No. 4, p. 152.

Shah, P. M., Amarasingham, R., and Oakley, C. M. (1965a). Brit. Heart Ұ., 27, 83 .

Yipintsoi, T., Amarasing

Sharpey-Schafer, E. P. (1955). Brit. med. 7., 1, 693.

Sharpey-Schafer, E. P. (1955)
(1956). Ibid., 1, 1072

Thomas, M., and Shillingford, J. (1965). Brit. Heart 7., 27, 17.

Wigle, E. D., David, P. R., Labrosse, C. J., and McMeekan, J. (1965) Amer. f. Cardiol., 15, 761 .

\title{
Reduction of Clotting in Scribner Shunts by Long-term Anticoagulation
}

\author{
A. J. WING,* M.A., B.M., M.R.C.P. ; J. R. CURTIS, † M.B., B.S., M.R.C.P. \\ H. E. DE WARDENER, $\ddagger$ M.B.E., M.D., F.R.C.P.
}

Brit. med. . ., 1967, 3, 143-145

Drukker et al. (1966) reported that 612 patients had been placed on regular dialysis treatment programmes in Europe by May 1966. For all these patients the Achilles heel of the treatment remains the arteriovenous shunt. The "life" of the shunts varies from centre to centre. Mean survival rates of between 2 and 14 months have been reported (Ramirez et al., 1966 ; Pendras and Smith, 1966).

Shunt life is influenced by infection and clotting. There have been six infections in 164 patient-years' experience in this unit. The frequency of clotting incidents is much higher ; 59 during the same period (cf. Erickson et al., 1966). This represents one clotting incident every 3.3 patient-months. At this rate, in a 10-bedded unit treating 30 patients 109 such incidents could be expected in the course of one year's operation.

When a shunt has clotted, declotting is necessary. Both events must be assumed to cause damage to the cannulated vessels. The clot causes anoxia to the intima, and the declotting procedure may traumatize the vessels. In addition it exposes the cannula site to the risks of infection. The risk of serious complications due to embolism appears to be slight. Clots are often released into the circulation at this procedure, and, despite the frequency with which it is carried out, there have been only isolated reports of collapse (Sokol, 1964) and of infected pulmonary emboli (Pendras and Erickson, 1965). Death has occurred on three occasions, each in a different unit, after declotting of arterial cannulae. Each patient became deeply unconscious after the procedure and some cerebral incident seems to have occurred. In our unit declotting is not carried out by the patients themselves and therefore they must come to the unit when they find that their shunt has clotted. A clotted shunt induces anxiety in the patient, for it is often the first of a series of clotting episodes and may be the signal that the cannula is coming to the end of its life. The significance

\footnotetext{
* Senior Registrar.

+ Lecturer in Medicine.

Department of Medicine, Charing Cross Hospital Medical School, Fulham Hospital, London W.6.
}

of the loss of a cannula does not escape these patients. Clotting episodes place demands on the staff " on call," and the incidence of such episodes dictates in part the staff requirements for these units.

Long-term oral anticoagulation with warfarin sodium has been given to some of our patients. This communication reports the results so far.

\section{Methods}

Anticoagulants are not given to any patient until a clotting episode has occurred. Therefore, after their original cannulation the patients are included in the untreated group. When a clot occurs oral anticoagulants are begun. Warfarin sodium is used and the prothrombin time is kept at 1.5 times the control time. Prothrombin times are estimated by Quick's one-stage method with the use of lung thromboplastin (Geigy). A loading dose of $30 \mathrm{mg}$. is given and 48 hours later a maintenance dose is prescribed. The maintenance dose required by our patients is in the range of 3-12 mg. a day. During the first 48-hour period 5,000 units (50 mg.) of heparin is injected six-hourly by the patient himself into the shunt through a medicated sleeve described elsewhere (Evans, 1966). If further clotting occurs despite adequate anticoagulation, a venogram is obtained. If there is reason to suspect that the arterial cannula is at fault -that is, poor flows during dialysis without high pressure in the "venous" line-an arteriogram is also obtained. If angiography shows an obvious cause for clotting or poor flows, then surgical correction is necessary.

Because of this method of selection the treated group is made up of patients who have shown themselves to be at risk, and therefore includes patients whose cannulae have already been damaged by at least one clotting episode. The untreated group is made up of patients whose shunts have never clotted, and also includes those patients whose anticoagulants have been discontinued. 


\section{Results}

Anticoagulation has reduced the frequency of clotting in the treated group.

Our total experience is now 195 patient-months. For 135 of these months anticoagulants have not been given, and during this time 52 clotting episodes have occurred. This represents a frequency of 4.6 clotting episodes per patient-year, or one every 2.6 patient-months. In the remaining 60 patient-months anticoagulants have been given and seven clotting episodes have occurred, a frequency of 1.4 clotting episodes per patient-year, or one every 8.6 patient-months.

Fig. 1 shows the difference between the incidence of clotting episodes in the treated and untreated groups.

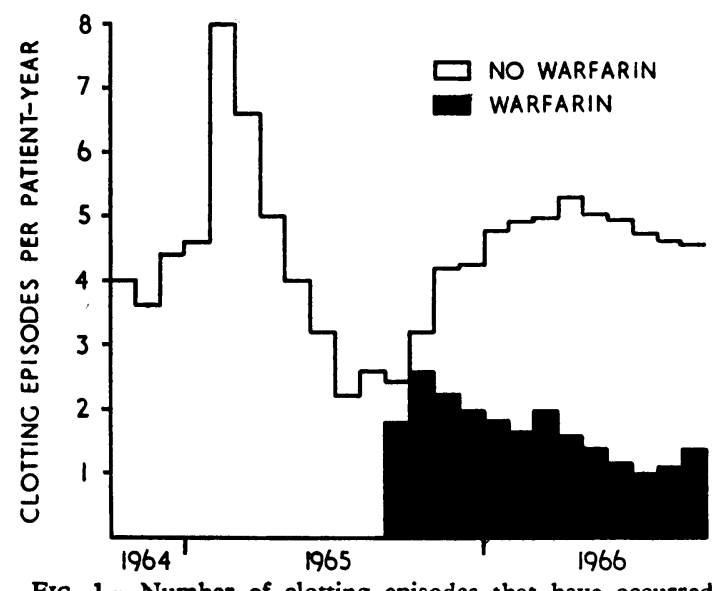

FIG. 1.-Number of clotting episodes that have occurred per patient-year is shown. The incidence of these epiper patent-year is shown. The incidence of these episodes has been calculated month by month on a cumulative basis. Thus the incidence at any one month represents total experience up to thit date. Open area $=$ Number of episodes per patient-year in patients not receiving oral anticoagulation. Blackened area $=$ Number of episodes per patient-year in patients treated with warfarin.

\section{Case Histories}

The following case histories illustrate the use and effect of anticoagulants in three patients (see Fig. 2).

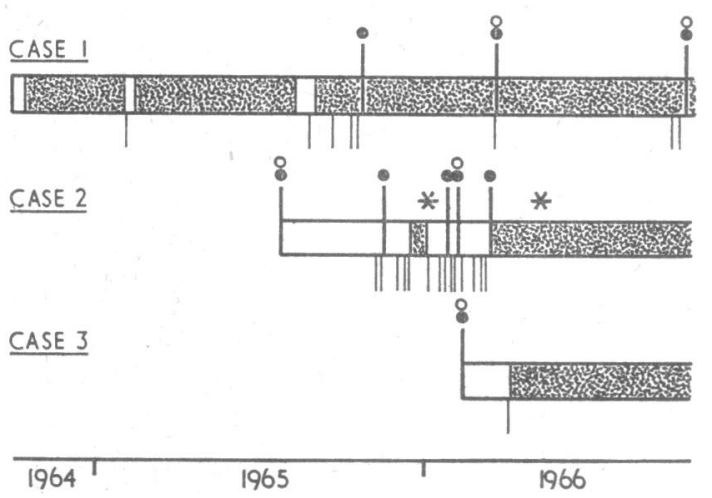

Fig. 2.-Each block represents the cannula history of individual patients, Cases 1, 2, and 3. For descriptions see text. Stippled area $=$ Period for which warfarin was given. Each vertical bar below each block represents a given. Each vercal bar below each block represents a clotting incident. Thick vertical bars extending above the blocks represent cannulation operations. Closed circle = New venous cannula. Open circle $=N$ ew arterial cannula. Asterisks = Haemorrhagic complications occurring in

Case 1.-A woman aged 24 with terminal renal failure due to chronic pyelonephritis had been on intermittent haemodialysis since 12 August 1964. Because of recurrent septicaemia, bilateral nephrectomy was carried out on 2 October 1964 . Splenectomy was also done at this time in case it should later be possible to offer the patient renal transplantation. After operation clotting of the shunt occurred and the platelet count was raised for three months $(375,000$ to $850,000 / \mathrm{cu}$. mm.). Warfarin was given. On two occasions, in February and August 1965, attempts were made to tail off the warfarin, but each time rebound clotting occurred. This patient is now on permanent anticoagulation. Recent clotting while adequately anticoagulated was associated with marked angiographic abnormalities.

Case 2.-A man aged 44 with terminal renal failure due to chronic pyelonephritis and gouty nephropathy had been on intermittent haemodialysis since 16 July 1965. After three months' good cannula function he damaged his shunt and eventually recannulation was necessary. There followed a rapid succession of clotting episodes, and four recannulations were carried out in three months. A first attempt at treatment with warfarin when the prothrombin time was kept at 2.0 times the control time resulted in a haematoma ; the drug was stopped and his shunt clotted. Anticoagulants were reintroduced in February 1966 and no further clotting has occurred. He developed a haemarthrosis in a previously gouty joint in April 1966 but there have been no further complications.

Case 3.-A woman aged 23 with terminal renal failure due to chronic pyelonephritis had been on intermittent haemodialysis since 15 January 1966. Previous transfusions, infusions, and cutdowns at another hospital had severely reduced the number of veins suitable for cannulation, and her first successful cannulation was in the left brachial artery and basilic vein. Clotting of the shunt occurred after six weeks. Fortunately, anticoagulation has so far prevented any further clotting. Considerable fibrin formation during dialysis has been noted in this patient.

\section{Complications}

There have been four haemorrhagic complications. Two spontaneous haematomas occurred in the treated group, and on both occasions the prothrombin time was 2.0 times the control time. One, in the neck, threatened respiratory obstruction. The haemarthrosis in one of Case 2's gouty joints required aspiration. One treated patient developed a haematoma in a cannulation wound.

\section{Discussion}

The risks of the use of anticoagulants are well documented (Hudson, 1965). They are those due to haemorrhage and those due to hypersensitivity. Of the four haemorrhagic complications in this unit two occurred when the prothrombin time was prolonged well above the 1.5 times the control which is now regarded as optimal. Should hepatitis develop, dosage requirements may change rapidly, and frequent estimations of the prothrombin time are indicated. Gastrointestinal haemorrhage and pericarditis are contraindications to the use of anticoagulants. Dangerous hypersensitivity reactions can be avoided by using warfarin as opposed to phenindione (Hollman and Wong, 1964).

Patients who clot their shunts repeatedly have, on average, a shorter shunt "life" (cf. Pendras and Smith, 1966). The use of warfarin in such patients has reduced the frequency of clotting and has prolonged the life of their shunts. We believe that the added risks are worth taking in those patients who are known to be at risk of clotting their shunts. Some patients do not have clotting problems. In our untreated group we have three patients totalling 2 years 10 months' experience who have never clotted their shunts. Erickson et al. (1966) have reported that cannulated haemodialysed patients have a higher level of blood-clotting factors than a random non-uraemic control group. They have also found that the level of clotting factors is higher in "clotters" than in " non-clotters." This work suggests that it may eventually be possible to predict which patients should receive anticoagulants.

There is a further difficulty in handling anticoagulants in these patients: once begun, they are difficult to withdraw. This has been attempted on six occasions in five patients, and on four of these occasions due care was taken to "tail off" the dosage. The other two occasions were regarded as serious haemorrhagic emergencies requiring abrupt cessation of anticoagulants. Four 
out of the six attempts to withdraw anticoagulants resulted in clotting of the shunts, and in three of these the site was lost within a fortnight. A further patient who discontinued his warfarin because of a misunderstanding promptly clotted his shunt.

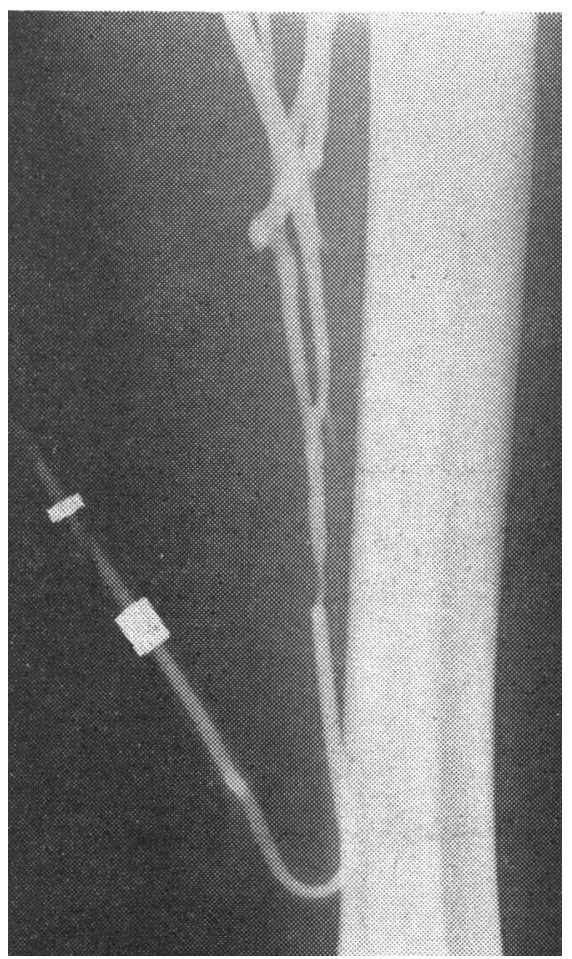

FIG. 3

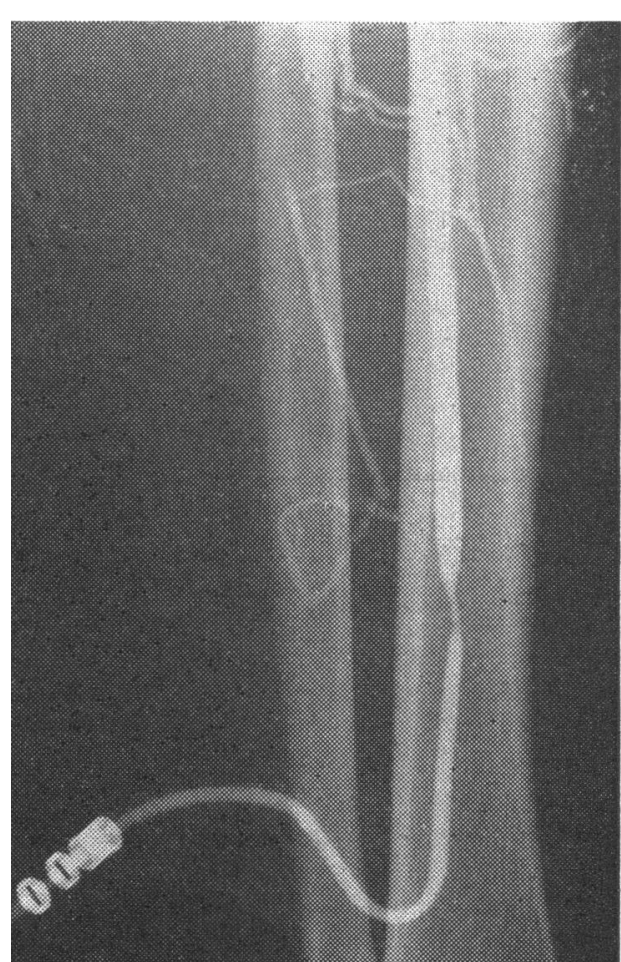

FIG. 4
Figs. 3 and 4 -Venograms showing stenotic lesions at cannulae tips. These are very commonly found. In both patients the cannula was successfully placed a little higher up the same vessel.

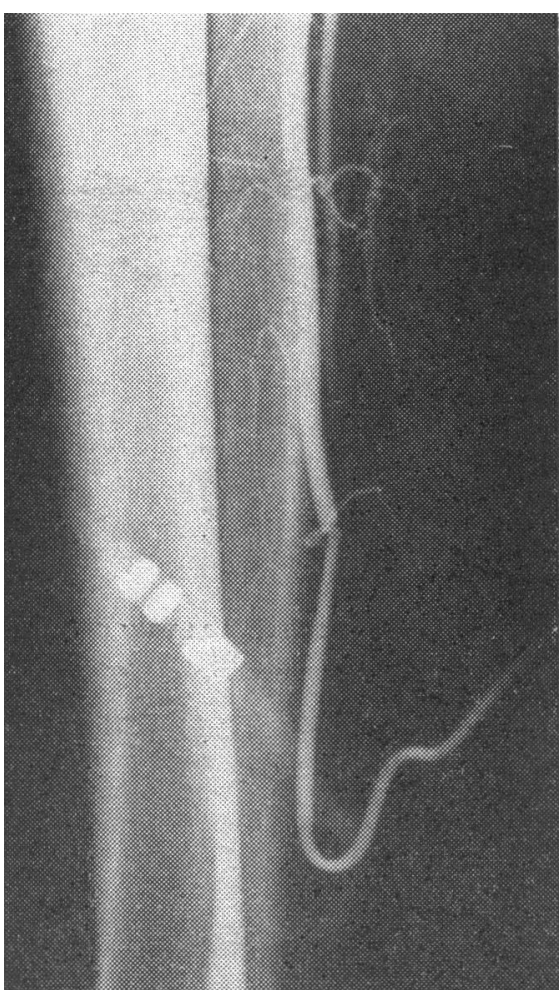

FIG. 5

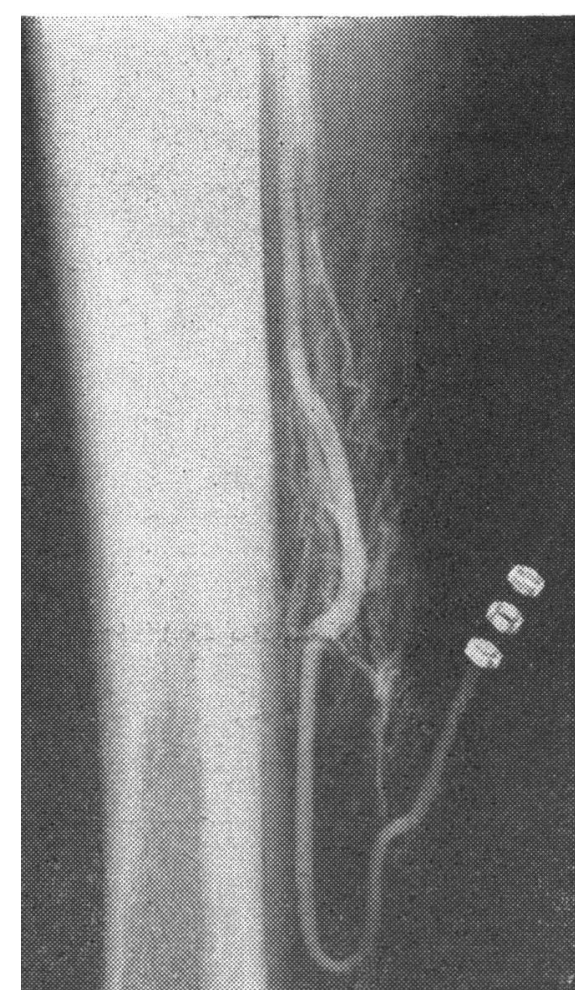

FIG. 6
FIG. 5.-Arteriogram showing angulation at junction of Teflon tip and vessel. This gave rise to poor flows during dialysis, and eventually clotting occurred. FIG. 6.-Arteriogram showing an Sbend deformity of the artery. The cannula had been inserted incorrectly in relation to the tendon bend deformity of the artery. The cannula had been inserted incorrectly in relation to the tendon the shunt clotted. Note the leash of small vessels. This shunt had previously been infected.
Clotting in the shunts is due in part to blood-clotting factors, because of this warfarin has reduced their frequency. Clotting may also be initiated if the patient is made hypotensive owing to excessive ultrafiltration during dialysis. There remain mechanical defects in the components of the shunt and structural defects in the cannulated vessels which may precipitate clotting. When repeated clotting of the shunt has occurred without hypotensive episodes and despite adequate anticoagulation, then a venogram and, if indicated, an arteriogram are obtained. Under these circumstances a structural defect in one or both vessels has always been demonstrable. Such abnormalities have included stenosis of the vessel near the cannula tip, malalignment, and aneurysmal dilatation (see Figs. 3-6). These radiographic appearances only serve to emphasize the extreme importance of careful surgery and expert cannula care. Attention to heparinization during dialysis is necessary to minimize fibrin formation, which may lead to deposition in the cannulated vein. Erickson et al. (1966) have observed one patient in whom such fibrin formation was a problem and who also suffered repeated clotting episodes. Warfarin abolished both.

\section{Summary}

Oral anticoagulation with warfarin has been given to a selected group of patients being treated by intermittent haemodialysis. The group was composed of patients whose shunts were known to be at risk because of previous clotting episodes. Treatment has decreased the frequency of clotting episodes and has prolonged the "life" of the shunts in this group of patients. Any success with the use of anticoagulants should not be allowed to detract from emphasis on accurate cannula placement and good cannula care, and on avoidance of hypotensive episodes.

\section{REFERENCES}

Drukker, W., Alberts, C., Ode, A., Roozendaak, K. J., and Wilmink, J. (1966). Proceedings European Dialysis Transplant Association, vol. 3, 90.

Erickson, R. V., Williman, M., and Pendras, J. P. (1966). Trans. Amer. Soc. artif. intern. Org., 12, 205.

Evans, D. B. (1966). Brit. med. Y., 2, 883.

Hollman, A., and Wong, H. O. (1964). Ibid., 2, 730.

Hudson, R. E. B. (1965). Cardiovascular Pathology, vol. 1, p. 197. London.

Pendras, J. P., and Erickson, R. V. (1965). Trans. Amer. Soc. artif. intern. Org., 11, 238.

- and Smith, M. P. (1966). Ibid., 12, 222. Ramirez, O., Swartz, C., Onesti, G., Mailloux, L., and Brest, A. N. (1966). Ibid., 12 220.

Sokol, A. (1964). In Proceedings of the Working Conference on Chronic Dialysis, Washington, 1964, p. 27. 